Methods We retrospectively identified and reviewed the records of all patients referred from a general respiratory clinic for oesophageal manometry and $\mathrm{pH}$ studies.

Results 112 patients were referred for oesophageal $\mathrm{pH}$ studies from respiratory clinic. The most common presenting symptom was cough (63 patients), other indications included recurrent chest infections (26), bronchiectasis (23) and pulmonary fibrosis (9). 110 patients tolerated the procedure; 74 patients $(67.3 \%)$ were found to have significant acid reflux.

33 patients were referred for surgical opinion. Reasons not to refer included patient refusal, poor lung function, obesity and resolution of symptoms. 25 patients had antireflux surgery.

$30 \%$ of patients reported an improvement or resolution of symptoms post surgery.

Conclusion Oesophageal studies and antireflux surgery are of benefit to a significant proportion of carefully selected patients from routine respiratory clinics.

Competing interests None.

Keywords manometry and $\mathrm{pH}$, respiratory.

\title{
Oesophagus
}

\section{PWE-092 A RETROSPECTIVE STUDY OF OUTCOME FOR PATIENTS REFERRED FOR OESOPHAGEAL STUDIES FROM A DISTRICT GENERAL HOSPITAL RESPIRATORY CLINIC}

doi:10.1136/gut.2011.239301.355

B Ebert, ${ }_{1}^{1}$ K Noble, ${ }^{2}$ S Vathenen, ${ }_{1}^{1}$ D Brocklebank, ${ }_{1}$ H Abusriwil, $^{3}$ D Aldulaimi ${ }^{1,}{ }^{*}$ 'Worcestershire Acute Hospitals NHS Trust, Redditch, UK; ${ }^{2}$ Oesophageal Laboratory, Birmingham Heartlands Hospital, Birmingham, UK; ${ }^{3}$ Respiratory Medicine, Dudley Road Hospital, Birmingham, UK

Introduction Oesophageal manometry and $\mathrm{pH}$ studies can be used to evaluate patients with atypical reflux symptoms, such as chronic cough, or recurrent chest infections, bronchiectasis and pulmonary fibrosis. Patients with demonstrated reflux that fail to respond to PPI therapy may be considered for antireflux surgery. Few studies have reported outcomes for patients referred for oesophageal studies from respiratory clinics based in district general hospitals. 